\title{
Neonatal hypoglycemia resulting in occipital cerebral injury
}

\author{
Kanupriya Vijay • Amit Agarwal
}

Received: 12 August 2010/Revised: 26 October 2010 /Accepted: 29 October 2010 /Published online: 5 November 2010

(C) Springer-Verlag 2010

A 3-day-old girl with transient hypoglycemia, born to a 27year-old mother with gestational diabetes, presented with seizures within 24 hours of birth. MRI of the brain revealed near symmetric areas of restricted diffusion involving bilateral occipital lobes and the splenium of corpus callosum, with bright signal on diffusion weighted imaging (DWI) (Fig. 1) and signal loss on apparent diffusion coefficient (ADC) maps (Fig. 2). These imaging findings were most consistent with hypoglycemic brain injury.

Radiological findings of neonatal hypoglycemia vary considerably depending on the degree and duration of hypoglycemia. The occipital lobes are most severely

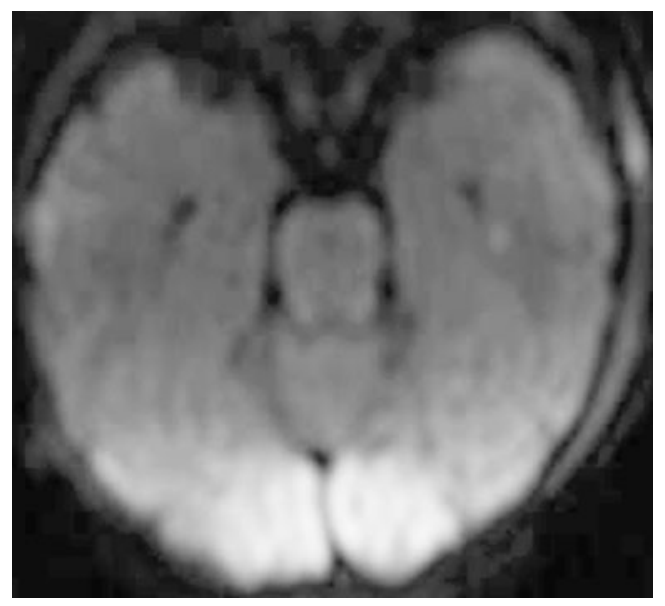

Fig. 1 Diffusion weighted MRI of the brain

\footnotetext{
K. Vijay $(\bowtie) \cdot A$. Agarwal

Department of Radiology,

Penn State University Hershey Medical Center,

500 University Drive,

Hershey, PA 17036, USA

e-mail: kvijay@hmc.psu.edu
}

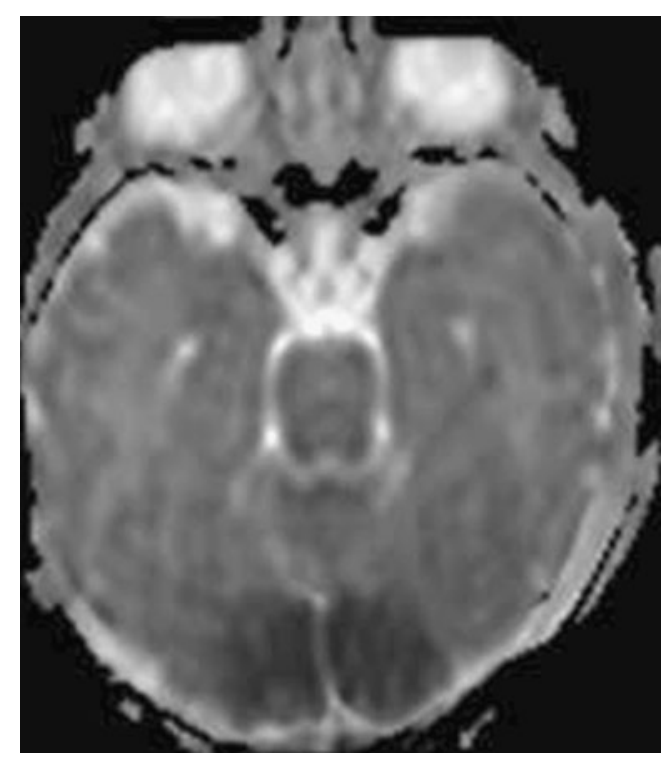

Fig. 2 ADC image

affected. Predominant involvement of the cortex at the base of cerebral sulci or vascular watershed regions, which is the hallmark of hypoxic-ischaemic encephalopathy, is not obvious [1]. The patterns of injury may, however, be more diverse with involvement of the basal ganglia, thalamus and the posterior limb of the internal capsule [2].

\section{References}

1. Kim SY, Goo HW, Lim KH et al (2006) Neonatal hypoglycaemic encephalopathy: diffusion-weighted imaging and proton MR spectroscopy. Pediatr Radiol 36:144-148

2. Burns CM, Rutherford M, Boardman JP et al (2008) Patterns of cerebral injury and neurodevelopmental outcomes after symptomatic neonatal hypoglycemia. Pediatrics 122:65-74 